\title{
Work Experience Led Programs and Employment
} Attainment

\author{
Submitted 11/12/20, $1^{\text {st }}$ revision 21/01/21, $2^{\text {nd }}$ revision 15/02/21, accepted 20/03/21
}

\section{Abstract:}

\author{
Miguel Baião ${ }^{1}$, Ilze Buligina
}

Purpose: This paper studied a ALMP to assess its effectiveness, the significance of public expenditure and the role of work experience on employment attainment.

Design/Methodology/Approach: The existing literature has produced, so far, contradictory findings regarding work experience led programmes. The authors studied a Professional Traineeship Programme (PTP) outcome, using a descriptive statistic to verify the employment attainment rate and characteristics, over 13 years of the programme implementation.

Findings: We found that the PTP has an employment attainment average rate of almost 3 out of 4 trainees. The regression analysis indicates clearly a strong positive linear relationship between the dependent and independent variables. The number of trainees has a keener contribution on the employment attainment figures but, apparently, the role of public expenditure is not decisive.

Practical Implications: The findings clearly may help policy makers to take grounded decisions regarding this sort of programmes. Concerning the policy implications, the conclusions may lead to the fact that the PTP should continue to be provided to unemployed people (both youth and the adult population) bearing in mind the good results in employment attainment.

Originality/Value: A scientific approach assessment of this PTP has never been done. It is clear research that may contribute to clear-cut the contradictory findings on this sort of ALMP.

Keywords: Professional traineeships, active labour market policies, employment, unemployment.

JEL Codes: E24, H52, J08, J24, M53, O15.

Paper Type: Research study.

Acknowledgements: The authors would like to acknowledge Helen Metcalfe for the English language revision and the helpful remarks.

Funding: This work was supported by FCT, I.P., the Portuguese national funding agency for science, research, and technology, under the Project UIDB/04521/2020.

${ }^{1}$ Corresponding author, Ph.D. in Economic Sociology. Associate Professor at Universidade Lusófona. Researcher at CSG/SOCIUS/ISEG (Lisbon School of Economics \& Management)/Universidade de Lisboa),Portugal,e-mail: miguel.santos@ulusofona.pt ${ }^{2}$ Ph.D. in Public Administration Researcher at the Faculty of Business, Management and Economics / University of Latvia, e-mail: ib11193@lu.lv 


\section{Introduction}

The European employment guidelines call on Member States to strengthen active labour market policies (ALMP) by increasing their effectiveness, targeting, outreach, coverage, as well as interplay with passive measures, stressing that these policies should aim to improve labour-market matching and support sustainable transitions (Council of the European Union, 2015). These strategic priorities have further been reinforced by the European Pillar of Social Rights indicating that everyone has the right to timely and tailor-made assistance to improve employment or selfemployment prospects, including the right to receive support for job search, training, and re-qualification (European Commission, 2017). Thus, nowadays ALMP have become one of the most important foundations of the European Employment Strategy (EES) (Council of the European Union, 2018).

While various active labour market programmes have been in use for many years in most countries, there is a growing awareness of the need to develop scientifically justified measures of the effectiveness of different ALMP (Kluve, 2010). Such research informed policy making is especially relevant, given the substantial investment in ALMP across Europe. However, when jointly interpreting the evidence among stakeholders to inform decisions, it is important that different parties share an understanding of what the evidence means within the current policy context and whether the issue needs to be reframed considering what has become known (Wills et al., 2016). In Portugal for more than a decade the Professional Training Programme (PTP) has been implemented as an ALMP, and this program is linked to the European Union employment policies to address labour market challenges. The present paper is based on a research on the PTP outcomes in Portugal and deals with the assessment of employment attainment after work experience led schemes.

The aim of the research was to find out if and to what extent the PTP, as an ALMP, has the potential to lead to employment and if this employment rate bears a relationship to the prior training and job placements in respective companies, as well as a relationship with public expenditure used on the scheme. Two initial research questions were put forward: Does the PTP scheme lead to employment in general or within the companies providing traineeships? Is this employment correlated with the number of successful participants and with the amount of public expenditure in the scheme? The study was implemented using descriptive statistics to verify the employment attainment rate and characteristics over 13 years of programme implementation.

To implement the research, a comprehensive literature study was carried out to review and clarify the inner concept and the existing many typologies, assessment methods and outcome measuring, the evaluation and its application for program design and refinement. In relation to the effectiveness of the ALMP a considerable number of references was identified indicating to a relatively low success rate and effectiveness of subsidised public sector job programmes (Heckman, Lalonde, and Smith, 1999; Card, Kluve, and Weber, 2010). 
In Sweden, for example, in analysing six Swedish active labour market programmes, no convincing results have been obtained that demonstrate the public funding is of decisive role, unless other relevant factors are contributing to the success of the program or scheme (Sianesi, 2008). From this perspective and taking into consideration the rather contradictory existing research findings, after the theoretical background we present the results and discussions of our study over the PTP in Portugal and the own relevance to the national ALMP and for the literature set in general, as it bears implications not only to the employment attainment but also to the issue of the effectiveness of public funds expenditure. Regarding the effectiveness of the public funds expenditure a regression analysis has been carried out. This study may be an additional tool to ground evidence-based decisions regarding ALMP for the future, to get more convincing data to verify cost-efficiency.

\section{Theoretical Background}

\subsection{Overview}

The subsidised PTP implemented in the Portuguese ALMP legislative framework (MTSSS, 2019) aims to deliver professional experience and/or on-job-training (within a maximum of a nine-month period), looking to endorse the integration of qualified unemployed youth into the labour market or to retrain the qualified unemployed adult population to secure their employment. The provision of on-thejob training or work experience led delivery schemes aims to develop, for the participants, firm experience or firm specific skills and might be promoted by any legal private company, entity, or body, with or without profit goals. The beneficiaries are unemployed people registered in the public employment services (PES) and mainly those who are: a) young people aged between 18 and 30, with at least a qualification level 2 of the European Qualifications Framework (EQF) and b) over the age of 30, if they have obtained a level EQF level 2 qualification or higher and are looking for a new job and have not developed professional activity in the preceding 12 months. There is a payment to the trainee, partially remunerated by the employer (from 20 up to $35 \%$ ) and the remaining percentage by public funds managed by the Institute for Employment and Vocational Training (IEFP).

Prior to analysing the theoretical framework that ground this kind of professional traineeship/work experience led schemes such as an ALMP, it is important to clarify the own concept. There are many typologies for ALMP (Santos, 2016). A recent one is proposed by Brown and Kottl (2015). These authors fragmented the ALMP into three groups linked with the aim labour demand, labour supply and labour market matching. In this last action there are three intended effects, increase inflow into employment, increase productivity and improve the quality of the match (Brown and Kottl, 2015). Thus, this paper is focused on the labour market matching category, specifically in the PTP. Another issue is to know what and how to assess an ALMP. 
According to Dar (2002) the impact calculations try to measure whether - and to which degree - participants profit from a specific ALMP. Outcome measures can diverge depending on the evaluator's choice. However, the most common outcomes are earnings and employment rates (Dar, 2002). So, according to this author, evaluations can then be used to: a) help to design new programmes/schemes; b) refine the program design; c) improve program targeting and d) identify ineffective programmes. For the purposes of informing policy decisions (Pierre, 1999), an assessment is not finished until one considers the costs of an ALMP. Regrettably, costs appear to be the least analysed aspect of ALMP (Dar, 2002).

Nowadays, ALMP have become one of the most important foundations of the EES (Council of the European Union, 2018) and are highly recommended as a set of tools to enhance employment and to tackle unemployment (Dorsett, 2006; OECD/European Union, 2015). Nevertheless, there are studies and research that recurrently concluded dissimilarly about their real effectiveness and usefulness (Bell, Blundell, and Van Reenen, 1999; European Commission, 2012; Heckman, Lalonde, and Smith, 1999; Jovan and Jonel, 2011; Kluve and Schmidt, 2002; Lain et al., 2014; Rosholm and Svarer, 2008; Sianesi, 2008; Vlandas, 2013) or even that benefits, at the individual level, in most ALMP appear modest (Calmfors and Skedinger, 1995; Card, Kluve, and Weber, 2010; Fay, 1996; Martin and Grubb, 2001; Meager, 2009; Richardson and Van Den Berg, 2002).

The measures (or key actions, or schemes or programmes) designed to provide subsidies to traineeships/employment to companies can undertake assorted formats, from country to country, according to diverse criteria, for example, the type of compensation (Cueto and Mato, 2006), the governance model (Lain et al., 2014), the scheme design (Vogel, 2015) or the on-the-job training format provided (Bell, Blundell, and Van Reenen, 1999; Cueto and Mato, 2006; Escudero, 2015). The model of funding may also be varied, being a fixed payment, a multilevel grant, or a lumpsum grant (Cueto and Mato, 2006). The scheme can likewise offer further services such as training (on-the-job, voluntary or as a prerequisite for participation) and/or other support (e.g., advisory mechanisms) (Banerji, Lin, and Saksonovs, 2014; Cueto and Mato, 2006; Lain et al., 2014).

\subsection{Contradictory Findings}

As several schemes are integrated into numerous national policy frameworks and for a number of years ago (Betcherman, Olivas, and Dar, 2014) there have been an abundant number of studies and research, that we have checked in order to get a comprehensive point of dissimilar views and insights over these occurrences. This literature review has covered micro-level evaluations (Meager, 2009) of ALMP interventions. In general, we have detected that there is some inconsistency between findings and between the evidence sources. The following citations illustrates this discrepancy. 
In the OECD's framework the study conducted by Fay (1996) revised the sort of evidence from programmes appraisals on the effectiveness of some ALMP. He identified some policy implications based on the assessments of public subsidies to promote employment within private companies: a) there are substantial deadweight ${ }^{3}$ and substitution ${ }^{4}$ effects from wage subsidies, however these schemes appear to increase employment slightly; b) subsidies targeted at the long-term unemployed may lead to employers hiring them; c) the evidence on who should be offered the subsidy -employer or employee - is not well researched; d) there is little evidence on the effectiveness of using subsidies to foster on-the-job training. Similar conclusions were also stated by Richardson and Van Den Berg (2002). However, they argue if it is also considered the time spent within the programmes then the net effect of participation in those programmes, on the mean unemployment duration, is near to zero.

A study conducted by Heckman, Lalonde and Smith (1999) to observe the effectiveness of ALMP and the methods used to evaluate their effectiveness, concluded that ALMP are frequently ineffective and for most participants the impact is discreet or even uncertain. Traineeships or on-the-job training programmes will likely have assorted effects, and the impact, if it occurs, will result from some combination of a) learning by doing; b) the usual training provided by the firm to new workers; c) incremental training beyond that provided to unsubsidised workers; $d$ ) eligibility legal rules of the programme. In addition, these researchers argue that the provision of subsidised on-the-job training/traineeships is particularly hard to monitor both because the format has proven difficult to measure and because trainees regularly do not distinguish that they have been treated any differently than their coworkers. On-the-job training programmes at private companies are all designed to lead to immediate employment. By providing these services, these programmes act as a form of job search for many participants.

Similar inferences were stated several years later by Card, Kluve, and Weber (2010) as they concluded that subsidised public sector job programmes are generally less successful than other forms of ALMP. On-the-job training programmes appear to be particularly likely to produce more positive medium-term than short-term impacts on participants.

In 2002, Calmfors, Forslund, and Hemstrom, among other findings, concluded that on-the-job training or experience led schemes: a) increase the productivity of job seekers, b) do not have positive effects on subsequent regular employment, and c)

\footnotetext{
${ }^{3}$ Deadweight loss: the programme outcomes are not different from what would have happened in the absence of the programme (Staneva et al, 2016).

${ }^{4} A$ worker hired in a subsidised job is substituted for an unsubsidised worker who would otherwise have been hired. The net employment effect is zero (Staneva et al, 2016).
} 
crowding out ${ }^{5}$ is significantly less than other schemes, but it exists. In general, public measures help to reduce unemployment, but simultaneously do not influence the aggregate level of employment. A supplementary significant conclusion of the study is that programmes lose their effectiveness with an increase in volume, so, in terms of policy making, it is advisable to keep a lower volume level.

Using panel data for 15 industrial countries, Estevão (2003) found that ALMP raised employment rates in the business sector in the 1990s. Amongst those policies, direct subsidies for job creation (including experience led schemes and on-the-job training) appears to be the most effective to enable employment. According to this author, it is not clear that ALMP are cost-effective from a public expenditure perspective.

A very interesting study was conducted by Carling and Richardson (2004) that estimated the comparative achievements of eight Swedish programmes to reduce the duration of participants' unemployment. The general results showed that the schemes where the participants receive (subsidised) work experience and training in companies have better outcomes and are more cost-effective than the programmes of standard vocational training. A second explanation is that valuable information is revealed to both the employer and the trainee when the latter spends time in the program at the working location. In addition, the more regular the work performed by the participant during the program, the greater information about the match becomes available. These conclusions were to some extent also verified by Callanan and Benzing (2014) as they argued that the completion of an internship is the most significant variable in terms of influence on the ability to get a career-oriented position.

Similar conclusions regarding the impact of on-the-job training/work experience schemes on employment were found by Betcherman, Olivas and Dar (2004). They assessed 159 scientific works in the context of developing and industrialised countries. The main and generic finding over the ALMP - training for the unemployed schemes - suggested that participants often benefit from these programmes in terms of higher employment rates but not in terms of higher earnings. The few evaluations that have taken place in developing countries shows a less positive picture. Programmes seem to work best with on- the- job training and active employer involvement. They have also found different effects according to the country profile: some youth training programmes in developing countries have much more positive impacts than those that are seen in industrialised countries. All-inclusive packages of services and programmes that are driven towards real workplaces experience and training and are carefully targeted are good design features.

Jespersen, Munch and Skipper (2008) found, for participants tracked from 1995 to 2005, that private job training schemes generates substantially higher earnings (through upcoming employment or self-employment). It turns out to be crucial to

${ }^{5}$ Occurs when fewer jobs are available to non-participants because of the programme; (Staneva et al, 2016). 
derive long-term treatment effects, since participants in employment programmes initially experience severe and long-lasting negative locking-in effects ${ }^{6}$ due to long duration programmes.

Studying the Swedish schemes, Sianesi (2008) found that individuals that completed a work experience scheme were found to subsequently display lower employment rates coupled with a higher probability of benefit collection than if they had searched further as openly unemployed. Analysing the Swedish experience on which type of program works best, she found that the programmes oriented towards subsidised workplace experience and on-the-job training are relatively more effective for participants' subsequent labour market success than vocational classroom training courses. Other local research, over two different schemes of subsidised temporary employment in Switzerland, conducted by Gerfin, Lechner, and Steiger (2005) investigated the effects on future employment odds. The team concluded that, from the unemployed standpoint, the subsidies for temporary jobs in "normal" firms subject to market pressure are superior to the "classical" employment programmes operating in areas without much private competition. Given that temporary jobs (or work experience led schemes) are also the most effective programmes, this suggests a clear-cut policy recommendation in favour of those schemes.

However, Gerfin, Lechner, and Steiger (2005) argued that this conclusion must be treated with some carefulness, because it disregards the indirect potential. There are fears that programmes like experience led schemes may lead to substitution of unsubsidised labour through subsidised labour (i.e., they may create unemployment for participants in the medium to long term). In other words, companies may be tempted to use experience-led scheme participants as cheap or subsidised manpower.

Using data from 20 OECD countries to conduct an explorative empirical analysis, a similar inference was made by Boone and Van Ours (2009) which assessed the impact of several types of ALMP on the unemployment rate. They found that expenditures on labour market training programmes have a positive effect and impact to reduce the unemployment rate. However, subsidised jobs do not seem to influence unemployment rates. Conversely Dorsett (2006) found that a period of subsidised employment is a more effective means of exiting unemployment and to assure unsubsidised employment.

Kluve (2006; 2010) argued in a different and dissimilar way. Training measures (including on-the-job training and work experience led schemes) are likely to have a modest impact on the improvement of employment rates. Subsidies and support programmes to employment had a 50\% positive effect, while training schemes showed a slight positive effect. According to this author, traditional training programmes are found to have a modest likelihood of recording a positive impact on

\footnotetext{
${ }^{6}$ This is a situation where in an individual is unwilling or unable to exit a position because of the regulations, taxes or penalties associated with doing so (Wunsch, 2016).
} 
the odds of post-program employment. Conversely to these schemes, private sector incentive programmes showed a significantly better performance (Kluve et al., 2005).

Unlike conclusions were verified by Forslund, Fredriksson, and Vikstrom (2011). They found that depending on the phase of the economic cycle (Cueto and Mato, 2006), different measures have different effects. They disclosed that in periods of recession, the greatest effects on employment are provided by training programmes than other public measures. On average (over the cycle), on-the-job training schemes are associated with smaller (negative) lock-in effects and smaller (positive) long term effects than labour market training. They found evidence that also showed the relative smaller size of the lock-in effect during recession periods. This same conclusion was confirmed at a later stage by Vlandas $(2011 ; 2013)$ and the specific effects on youth employment by Choudhry, Marelli, and Signorelli (2013).

Brown and Koettl (2015) undertook a study assessing the cost-effectiveness of ALMP. They concluded that ALMP that are designed to create employment, such as on-the-job training, perform much better in terms of cost-effectiveness (mainly during economic recoveries), whereby the outsiders' attachment to the labour market is strengthened. Simultaneously, the outflow out of unemployment is supported and labour market persistence is reduced. In the same sense, Escudero (2015) found that public expenditure in training (in different formats) and direct job creation measures (including work experience-led schemes) show the most efficient results. The policy cluster appears to have a significant unemployment reducing effect and a substantial employment and labour force participation expanding effect for the overall populations.

Specifically targeted on young people, the study of Eichhorst and Rinne (2014) draws a few general conclusions: a) employment interventions tend to be more fruitful in developing and transition countries than in advanced economies, b) there is no consensus in the literature about the explanations for this finding, c) possible explanations that are cited in literature covers differences in the meaning of "disadvantaged" youth, as well as systemic dissimilarities in labour market governance, d) youth programmes have a lower probability to induce positive impacts in those labour markets where legal bases are too rigid, e) if protective employment rules create barriers for participants, ALMP will not be able to overcome these barriers, f) policy development and implementation should thus take a comprehensive approach to improving youth employment.

Regarding the differences in adult or young unemployment and employment driven schemes Staneva et al. (2016), conducted a comprehensive literature review over different ALMP evaluations. This team found that the international evidence provides mixed or even contradictory conclusions on the effectiveness of youth specific ALMP among young people and the adult population. It is, however, difficult to successfully compare since the results may be contingent on the business cycle phase, formal features of the labour market, the sort of scheme in operation and the span of the evaluation. In terms of the nature of ALMP, Staneva et al. (2016) found evidence that 
wage subsidy programmes are more effective than training or public works and, consistent with this, programmes benefit from links to the private sector.

\section{Methodology}

\subsection{Data}

We have used the IEFP's statistical database (IEFP, 2019) that encompasses data over a 13-year period, from 2005 until 2017. This database covers the data of 442,168 trainees as well the annual public expenditure on the PTP. The data related with the participants is fragmented in:

- $\quad$ number of participants that finished in the year X;

- number of participants hired by the companies/enterprises that provided the traineeship;

- $\quad$ number of participants that achieved self-employment;

- $\quad$ number of participants that are unemployed;

- number of participants that got other employment solutions not related with the PTP.

\subsection{Hypotheses}

Our initial questions were: Does the Professional Traineeships Programme scheme lead to employment in general or within the companies providing traineeships? Is this employment correlated with the number of successful participants and with the amount of public expenditure?

Therefore, the first question may be replied based on a simple descriptive statistic.

To answer the second question and considering our literature review, we propound the following hypotheses:

$\mathrm{H}_{0}$ The employment achievement is not related with the number of successful participants and the amount of public expenditure.

$\mathrm{H}_{\mathrm{a}}$ The employment achievement is related with the number of successful participants and the amount of public expenditure.

As this study is a micro-level evaluation, we have used the classification proposed by Meager (2009), by defining measures of overall "ALMP participation" and "public expenditure" as independent variables. As dependent variable we have set the "employment achievement" (i.e., \% of participants hired by the traineeship provider companies or those ones that got employment after the successful participation in the PTP). 


\section{Results and Discussion}

The IEFP's database returns the values in Table 1. Regarding the first question that led this study- Does the Professional Traineeships Programme scheme lead to employment in general or within the companies providing traineeships? - we can conclude that a mean of $51.6 \%$ of participants become employed by the company providing traineeships, while a mean of 4,2\% became self-employed. In 2013 and in 2015 the proportion of participants employed by the company providing traineeship were $101.5 \%$ and $100.7 \%$ respectively. These figures indicate that all successful participants in the year were employed at the companies and some additional participants, from previous years, also got employment in those companies. In total the employment attainment rate mean for the PTP is $71.2 \%$, with a minimum of $30.01 \%$ in 2006, a maximum of $137.04 \%$ in 2014 and a Standard Deviation of $42.4 \%$. So, almost 3 out of 4 successful trainees got a job after the programme.

In total there were changes in the legal bases in eight different years. The minimum percentage of participants $(8.9 \%)$ that got employment at the company providing traineeship was in 2009. This was the first year with changes. In the peak of economic crisis (2011-2015) this programme suffered changes in the legal bases every single year, but it shows the maximum and the highest values of trainees enrolled (Figure 1). Simultaneously, the maximum of trainees enrolled in the programme was reached in 2015 (72.161).

Figure 1. Total Trainees enrolled in PTP (2015-2017)

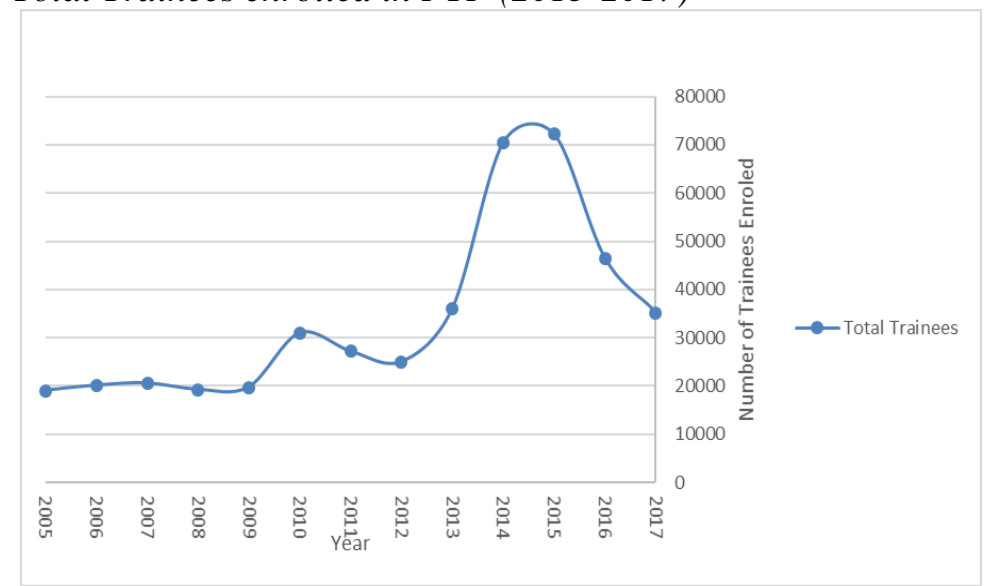

Source: Own calculations using IEFP data

Concerning the second question that leads this study- Is this employment related with the number of successful participants and with the amount of public expenditure? we have tested $\mathrm{H}_{0:}$ The employment achievement is not related with the number of successful participants and the amount of public expenditure. 
Table 1. Data for the PTP participants, Employment and Expenditure (2005-2017)

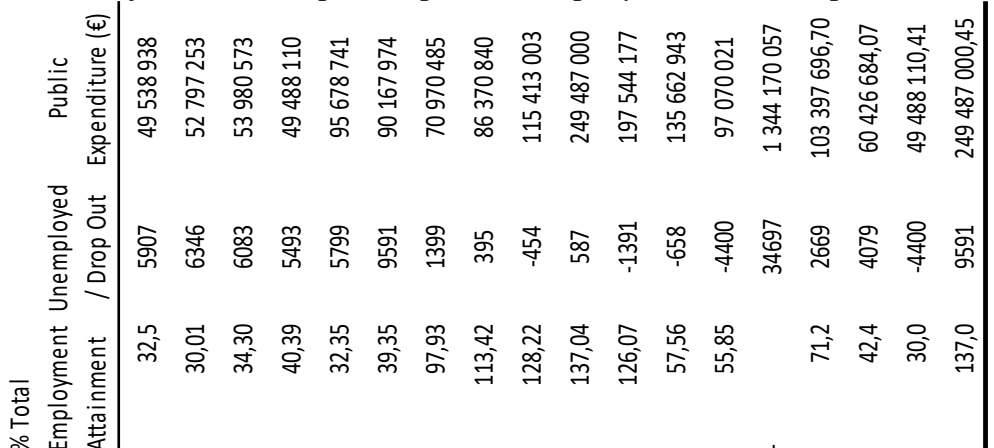

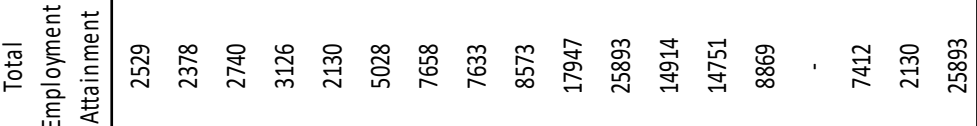

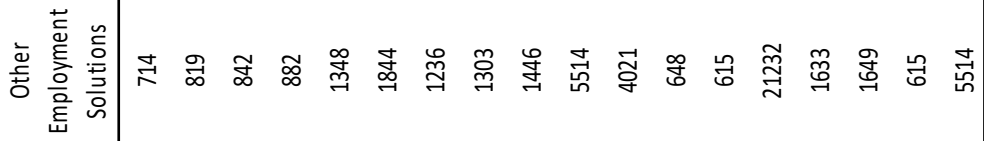
aे

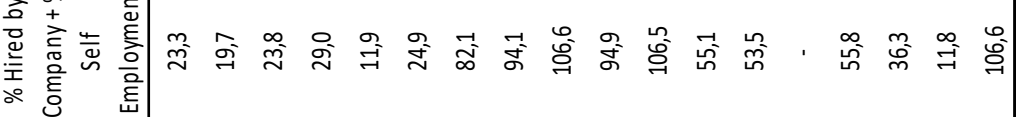

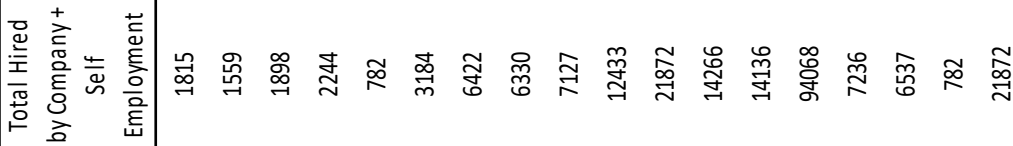

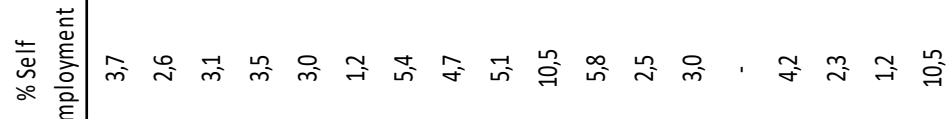

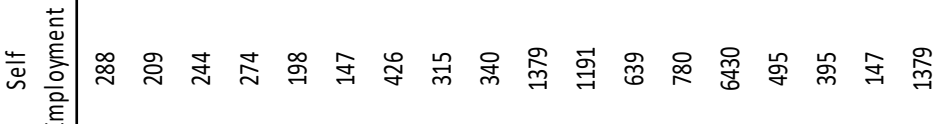

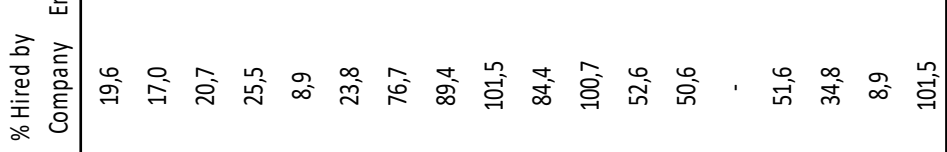

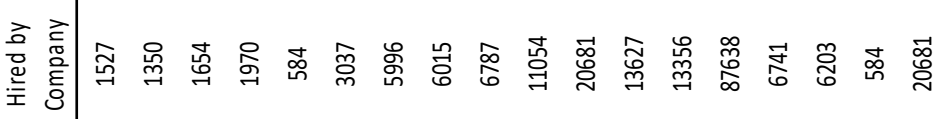

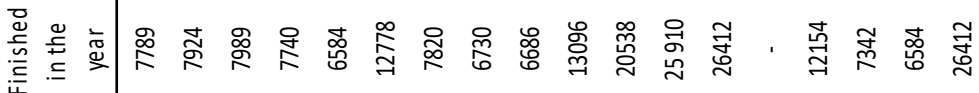

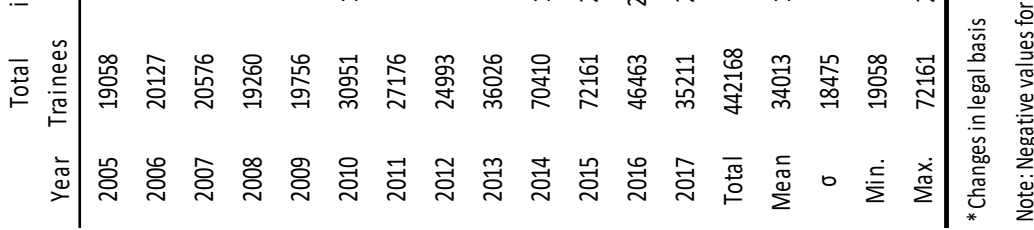
Source: IEFP's database. 
Therefore, to check if there is any relation between the employment achievement, or other explanatory variables (Vlandas, 2011), and the number of successful participants and the amount of public expenditure we have decided to apply a Regression Analysis. Thus, we tried to infer if the dependent variable "employment achievement" has any relation with both independent variables "number of successful participants" and the "amount of public expenditure" and in case of a positive answer if we can estimate the employment attainment rate in the future PTP, by fitting a linear equation to the observed data.

After performing the regression assumptions (Gelman \& Hill, 2006), we also performed the outliers' detection to data, due to the regression analysis sensitivity to extreme values (Hatcher, 2013). We have used a Boxplot for each independent variable, and we have found that there is one outlier at the "Public Expenditure" variable (Figure 2).

Figure 2. Boxplot for "Public Expenditure"

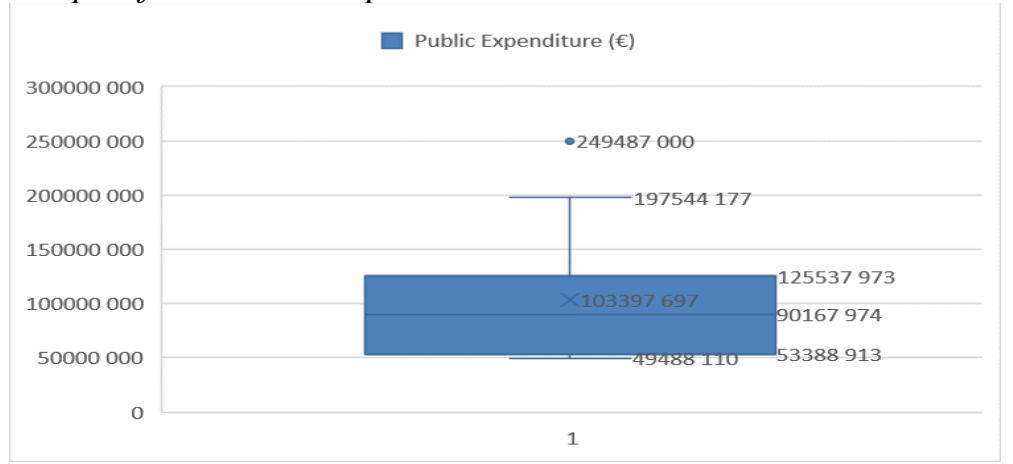

Source: Own calculations using IEFP data.

The identified outlier is the value for the year 2014. However, it does not mean that this data should inevitably be eliminated (Gelman and Hill, 2006; Hatcher, 2013). The exclusion of data can be dangerous, whereas this may end up destroying some important data information. An alternative method is to perform the regression analysis both with and without these outliers and inspect their detailed influence on the results (Gelman \& Hill, 2006; Hatcher, 2013). So, after performing both regression analysis, with and without the outlier, the regression statistics differences are negligible. So, we choose to keep the data for 2014. The regression statistics are described in Table 2.

The correlation coefficient (Multiple R) shows that the linear relationship is 0.90 . According to Ratner (2009), values between 0.7 and 1.0 indicate a strong positive linear relationship through a firm linear rule. So, our Multiple $\mathrm{R}$ indicates clearly a strong positive linear relationship. The $\mathrm{R}^{2}(0.81)$ indicates that $81 \%$ of variability of the dependent variable is explained by the explanatory variables. However, as we have two independent variables, we must look at the Adjusted $\mathrm{R}^{2}$ (Ratner, 2009). The Adjusted $\mathrm{R}^{2}(0.78)$ shows a $78 \%$ of explanation, meaning that the remainder of the 
variability $(22 \%)$ is due to some effects (other explanatory variables) that have not been included in this analysis (Ratner, 2009; Wagner, 2016).

Table 2. Regression Statistics

\begin{tabular}{lr}
\hline Summary & \\
Multiple R & 0,905516709 \\
\hline R Square & 0,81996051 \\
\hline Adjusted R Square & 0,783952612 \\
Standard Error & 2883,133449 \\
\hline Observations & 13 \\
\hline
\end{tabular}

Source: Own study.

On other hand, the ANOVA output is shown in Table 3.

Table 3. ANOVA

\begin{tabular}{|c|c|c|c|c|c|c|}
\hline & $d f$ & SS & MS & $F$ & Significance $F$ & \\
\hline Regression & 2 & 378577372,2 & 189288686,1 & 22,771685 & 0,000189164 & \\
\hline Residual & 10 & 83124584,83 & 8312458,483 & & & \\
\hline \multirow[t]{2}{*}{ Total } & 12 & 461701957,1 & & & & \\
\hline & Coefficients & Standard Error & tStat & $P$-Value & Lower 95\% & Upper 95\% \\
\hline Intercept & $-4334,372626$ & 1831,777618 & $-2,366211151$ & 0,039532 & $-8415,82751$ & $-252,9177462$ \\
\hline Finished in the year & 0,4954996 & 0,126651492 & 3,912307636 & 0,0029024 & 0,21330249 & 0,777696711 \\
\hline Public Expenditure & 4,88762E-05 & $1,539 \mathrm{E}-05$ & 3,175831059 & 0,0098892 & $1,4585 \mathrm{E}-05$ & $8,31673 \mathrm{E}-05$ \\
\hline
\end{tabular}

Source: Own study.

The question whether the correlation is statistically significant was also assessed. Using a $\alpha=0.05^{7}$ and looking up to P-value it is clearly lower $(0,002$ and 0,009$)$, so it can be concluded that the correlation is statistically significant (Leech, Barrett, and Morgan, 2014). Since the P-value is smaller than 0.05 , we reject the null hypothesis $\mathrm{H}_{0}$ (that the variables are unrelated). Thus, there is a relationship between the dependent and the independent variables. The linear regression equation is given by:

Employment Attainment $=-4334.37+0.49$ Finished in the Year +4.88 E-05 Public expenditure

So, we conclude that the regression model is a good fit for the data. Note that all the coefficients are significant. That $\mathrm{R}^{2}=.0,81$ indicates that a good deal of the variability of Employment Attainment is captured by the model. Despite the P-values (0.002 and $0.009)$ are clearly smaller than 0.05 the values of the coefficients $(0.49$ and $4.88 \mathrm{E}-05)$ are also small. So, the Public Expenditure variable apparently is not decisive for the

${ }^{7}$ According to Head et al. (2015) it is the most used value for social sciences studies. 
Employment Attainment in PTP. The number of successful participants has its own role on the Employment Attainment. Perhaps other variables, such as the legal basis (that in our data display several changes from 2009 until 2017) (Ebbinghaus and Eichhorst, 2006; Eichhorst and Rinne, 2014), political determinants (Vlandas, 2013) or the economic cycle status (Cueto and Mato, 2006; Staneva et al., 2016) may have additional explanatory power.

For IEFP/ALMP these results may indicate that: a) the current policy of attracting people and companies to the scheme should be kept and stimulated and b) major attention should be paid on the use of public expenditure on this scheme, specially by studying the possibility, soon, to scaling up fixed costs or by introducing standard costs.

In general, we had some limitations in this study: a) the presentation of the data within the statistical documents of IEFP which were characterised by changes in the presentation and calculation; b) there were many changes in the legal basis and regulations, mainly since 2009 and c) even though the programme has run for over 14 years there is a lack of aggregate data for 2018 and therefore we had only 13 complete years to analyse.

\section{Conclusions}

The aim of this article was to examine the effects of the PTP on employment attainment by successful participants on the programme. This paper started by reviewing the definitions, concepts and theoretical background that could ground our study.

Regarding the first starting question - Does the Professional Traineeships Programme scheme led to employment in general or within the companies providing traineeships? - we found that in total the employment attainment rate mean for the PTP is $71.2 \%$. So, almost 3 out of 4 successful trainees got a job after the programme.

On the other hand, a mean of $51.6 \%$ participants became employed by companies offering traineeships. This finding is in line with the works of Cueto and Mato, (2006), Gerfin, Lechnerb, and Steigerc (2005) and Vogel (2015). Thus, this is important to captivate, within the company, the individual skills achieved during the traineeship. We have also found that there are large annual differences in employment attainment rate within the company providing a traineeship. The weakest year of employment attainment was 2009 (with only 8.9\%) and on the other hand the better years were 2013 and 2015.

The proportion of participants employed by the company traineeship providers were $101.5 \%$ and $100.7 \%$ respectively. Yet, these figures over $100 \%$ indicate that all successful participants in that year were employed at the companies and some more participants, from previous years, also got employment in those companies. This result is translated to the overall annual employment attainment rate, with $128.2 \%$ 
and $137.04 \%$ respectively. Some of the positive results concerning employment maybe perhaps linked with the economic cycle, as claimed by Cueto and Mato, (2006) and changes within the legal basis, as argued by Heckman, Lalonde, and Smith (1999) or regulations (Ebbinghaus and Eichhorst, 2006).

Regarding the second starting question - Is this employment related with the number of successful participants and with the amount of public expenditure in the scheme? - we have used the "Employment Attainment" as the dependent variable and the "Number of Successful Participants" and the "Public Expenditure" as independent variables to perform a regression analysis. Thus, the second conclusion that can be drawn addresses the fact that there is a strong positive linear relationship between the independent and dependent variables.

The number of successful participants that "finished in the year" has more explanatory power that the variable "Public Expenditure". So, the variable "Public Expenditure" apparently is not decisive for the Employment Attainment in the PTP. The statistical results may indicate that: a) the number of successful participants in the year has a role on the Employment Attainment, b) the Public Expenditure in the PTP are slightly responsible for the Employment Attainment creation positions and c) perhaps there are other variables such as the legal basis/regulations (as argued by Ebbinghaus and Eichhorst, 2006; Eichhorst and Rinne, 2014 and Heckman, Lalonde, and Smith (1999), political determinants (concluded also by Vlandas, 2013) or the economic cycle period (as claimed by Cueto and Mato, 2006; Staneva et al., 2016) that may have additional explanatory power.

Concerning the policy implications, these conclusions may lead to the fact that the PTP should continue to be provided to unemployed people (both youth and the adult population) bearing in mind the good results in employment. This implication is in line with the conclusions of Gerfin, Lechnerb, and Steigerc (2005).

Finally, more comprehensive studies and evaluations are needed to assess, in depth, if the use of public expenditure to promote employment should continue as it is, or if it needs to be revamped, to increase the cost-efficiency, as concluded by Carling and Richardson (2004).

We had some limitations in this study. First, the presentation of the data within the statistical documents of the IEFP. There were changes on the presentation and calculation during the period. This was due to changes in the legal basis and regulations, which have mainly taken place since 2009. The second one is the lack of aggregate data for 2018. In addition, the way that the data is presented do not allows to assess causality due to the lack of a counterfactual measures and when/if locking in crowding out and substitution effects might be relevant. In future the IEFP should consider updating and/or change the way how data are collected and improved to allow impact studies. 
For future research, we believe that some studies could be undertaken around the impact of political determinants, the economic cycle, and the legal basis/regulations on the outcomes of this ALMP.

\section{References:}

Banerji, A., Lin, H., Saksonovs, S. 2014. Youth Unemployment in Europe: Okun's Law and Beyond. IMF Working Paper. WP/15/5. Washington DC. Available at: https://www.imf.org/en/Publications/WP/Issues/2016/12/31/YouthUnemployment-in-Advanced-Europe-Okuns-Law-and-Beyond-42608.

Bell, B., Blundell, R., Van Reenen, J. 1999. Getting the Unemployed Back to Work: The Role of Targeted Wage Subsidies. Journal of International Tax and Public Finance, Volume 6, Issue 3, 339-360.

Betcherman, G., Olivas-Dar, A. 2004. Impacts of Active Labor Market Programs: New Evidence from Evaluations with Particular Attention to Developing and Transition Countries. Social Protection Discussion Paper Series. No 0402. Social Protection Unit, Human Development Network. The World Bank.

Boone, J., Van Ours, J.C. 2009. Bringing Unemployed Back to Work: effective active labour market policies. De Economist, 157, 293-313.

Brown, A., Kottl, J. 2015. Active labor market programs - employment gain or fiscal drain? IZA Journal of Labor Economics, 4, 12. DOI:10.1186/s40172-015-0025-5.

Callanan, C., Benzing, C. 2014. Assessing the Role of Internships in the Carrer-oriented Employment of Graduating College Students. Education and Training, 46, 2, 82-89.

Calmfors, L., Forslund, A., Hemström, M. 2002. Does active labour market policy work? Lessons from Swedish experiences. Swedish Economic Policy Review, 8(2), 61124.

Calmfors, L., Skedinger, P. 1995. Does active labour-market policy increase employment? Theoretical considerations and some empirical evidence from Sweden. Oxford Review of Economic Policy, 11, 1, 91-109.

Card, D., Kluve, J., Weber, A. 2010. Active Labour Market Policy Evaluations: A MetaAnalysis Economic Journal, 120, 452-477.

Carling, K., Richardson, K. 2004. The relative efficiency of labor market programs: Swedish experience from the 1990s. Labour Economics, 11, 335-354.

Choudhry, M.T., Marelli, E., Signorelli, M. 2013. Youth and total unemployment rate: the impact of policies and institutions. Rivista Internazionale di Scienze Sociali, Vita e Pensiero, Pubblicazioni dell'Universita' Cattolica del Sacro Cuore, 121(1), 63-86.

Cueto, B., Mato, J. 2006. An analysis of self-employment subsidies with duration models. Applied Economics, 38, 1, 23-32.

Council of the European Union. 2015. On broad guidelines for the economic policies of the Member States and of the European Union. Council Recommendation (EU) 2015/1184 of 14 July 2015. Available at: https://eur-lex.europa.eu/legalcontent/EN/TXT/?uri=OJ:JOL_2015_268_R_0005.

Council of the European Union 018. Council Decision (EU) 2018/1215 of 16 July 2018. Available at: https://eur-lex.europa.eu/legalcontent/EN/TXT/PDF/?uri=CELEX:32018D1215andfrom=EN.

Dar, A. 2002. Impact Evaluation: Techniques for Evaluating Active Labor Market Programs. World Bank Employment Policy Primer, 2. Available at: https://openknowledge.worldbank.org/bitstream/handle/10986/11829/301310ENG LISH0EPPNno120Impact0evaluation. $p d f$ ?sequence $=1$ andisAllowed $=\mathrm{y}$. 
Dorsett, R. 2006. The new deal for young people: effect on the labour market status of young men. Labour Economics, 13, 405-422.

Ebbinghaus, B., Eichhorst, W. 2006. Employment Regulation and Labor Market Policy in Germany, 1991-2005. Discussion Paper Series. IZA DP No. 2505. Institute for the Study of Labour, Bonn.

Eichhorst, W., Rinne, U. 2014. Promoting youth employment through activation strategies. Employment Working Paper, No. 163. International Labour Office, Youth Employment Programme, Employment Policy Department: Geneva.

Escudero, V 2015. Are active labour market policies effective in activating and integrating low-skilled individuals? An international comparison. ILO Research Department Working Papers, No. 3. International Labour Office, Geneva.

Estevão, M. 2003. Do Active Labor Market Policies Increase Employment? IMF Working Papers, WP/03/234. Ed. International Monetary Fund / European Department. European Commission. 2012. Moving Youth into Employment. Communication from the Commission to the European Parliament, the Council, the European Economic and Social Committee and the Committee of the Regions. SWD, Brussels.

European Commission. 2017. Establishing a European Pillar of Social Rights. Communication from the Commission European Parliament, the Council, the European Economic and Social Committee and the Committee of the Regions. COM/2017/0250 final. Available at: https://eur-lex.europa.eu/legalcontent/en/ALL/?uri=CELEX\%3A52017DC0250.

Fay, R.G. 1996. Enhancing the Effectiveness of Active Labour Market Policies: Evidence from Programme Evaluations in OECD Countries. OECD Labour Market and Social Policy Occasional Papers, No. 18, OECD Publishing, Paris. DOI: http://dx.doi.org/10.1787/560806166428.

Forslund, A., Fredriksson, P., Vikström, J. 2011. What active labour market policy works in a recession? Institute for Labour Market Policy Evaluation Working Papers, 2011:2. Uppsala.

Gelman, A., Hill, J. 2006. Data analysis using regression and multilevel/hierarchical models. Cambridge: Cambridge University Press.

Gerfin, M., Lechner, M., Steiger, H. 2005. Does subsidised temporary employment get the unemployed back to work? An econometric analysis of two different schemes. Labour Economics, 12, 807-835.

Hatcher, L. 2016. Advanced Statistics in Research: Reading, Understanding, and Writing Up Data Analysis Results. Ed: Shadow Finch Media LLC.

Head, M., Holman, L., Lanfear, R., Kahn, A.T., Jennions, M.D. 2015. The extent and consequences of p-hacking in science. PLoS Biology, 13(3), e1002106. Available at: https://www.ncbi.nlm.nih.gov/pmc/articles/PMC4359000/pdf/pbio.1002106.pdf.

Heckman, J.J., Lalonde, R.J., Smith, J.A. 1999. The economics and econometrics of active labor market programs. In: Ashenfelter, O., Card, D. (eds.). Handbook of Labor Economics, Vol. 3A, Amsterdam and New York: Elsevier, 1865-2095.

IEFP. 2019. Relatório de Execução Física e Financeira. Available at: https://www.iefp.pt/estatisticas.

Jespersen, S., Munch, J., Skipper, L. 2008. Costs and benefits of Danish active labour market programmes. Labour Economics, 15, 859-884.

Jovan, Z., Jonel, S. 2011. Reviewing development of active labour market policies and the evaluation techniques. MPRA Munich Personal RePEc Archive. MPRA Paper No. 35282. Available at: https://mpra.ub.uni-muenchen.de/35282/ . 
Kluve, J. 2006. The Effectiveness of European Active Labor Market Policy. Discussion Paper No. 2018. RWI Essen and IZA Bonn.

Kluve, J. 2010. The effectiveness of European active labour market programs. Labour Economics. DOI:10.1016/j.labeco.2010.02.004.

Kluve, J. et al. 2005. Study on the Effectiveness of ALMP. DG Employment Social Affairs and Equal Opportunities, Brussels.

Kluve, J., Schmidt, C. 2002. Can training and employment subsidies combat European unemployment? Economic Policy, 17, 35, 409-448.

Lain, D. 2014. Evaluating internships in terms of governance structures. European Journal of Training and Development, 38 6, 588-603.

Leech, N., Barrett, K., Morgan, G. 2014. IBM SPSS for Intermediate Statistics: Use and Interpretation, Fifth Edition. Routledge, London.

Martin, J.P. 2014. Activation and Active Labour Market Policies in OECD Countries: Stylized Facts and Evidence on their Effectiveness. IZA Policy Papers Series, IZA Policy Paper No. 84. Available at: www.iza.org.

Martin, J.P., Grubb, D. 2001. What works and for whom: A review of OECD countries' experiences with active labour market policies. Swedish Economic Policy Review, $8,2,9-60$.

Meager, N. 2009. The role of training and skills development in active labour market policies. International Journal of Training and Development, 13, 1, 1-18.

MTSSS. 2019. Portaria n. ${ }^{\circ}$ 70/2019. Available at: https://dre.pt/application/file/a/120107871.

OECD/European Union. 2015. The Missing Entrepreneurs 2015: Policies for Selfemployment and Entrepreneurship, OECD Publishing, Paris. http://dx.doi.org/10.1787/9789264226418-en.

Pierre, G. 1999. A framework for active labour market policy evaluation. Employment and Training Papers number 49. Employment and Training Department/International Labour Office Geneva, Geneva.

Ratner, B. 2009. The correlation coefficient: Its values range between $+1 /-1$, or do they? Journal of Targeting, Measurement and Analysis for Marketing, 17, 2, 139-142.

Richardson, K., Van Den Berg, G.J. 2002. The Effect of Vocational Employment Training on the Individual Transition Rate from Unemployment to Work. IFAU - Institute for Labour Market Policy Evaluation, Working Paper No. 2002:8. http://dx.doi.org/10.2139/ssrn.319060.

Rosholm, M., Svarer, M. 2008. The Threat Effect of Active Labour Market Programmes. Scandinavian Journal of Economics, 110(2), 385-401.

Santos, M.B. 2016. Beyond skill mismatch. Why there are so many unfilled vacancies and simultaneously high unemployment rates? R-LEGO - Revista Lusófona de Economia e Gestão das Organizações, No 2, 9-27.

Sianesi, B. 2008. Differential effects of active labour market programs for the unemployed. Labour Economics, 15, 370-399.

Staneva, A. et al. 2016. The effect of Active Labour Market policies on Youth Unemployment -Literature Review - Final Report. Social Research, No 344/2016WISERD, Swansea University.

Vlandas, T. 2011. The dependent variable problem in quantitative studies of Active Labour Market Programmes. Uncovering hidden dynamics? Working Papers on the Reconciliation of Work and Welfare in Europe. REC-WP 03/2011. RECWOWE Publication, Dissemination and Dialogue Centre, Edinburgh.

Vlandas, T. 2016. Mixing apples with oranges? Partisanship and active labour market policies in Europe. Journal of European Social Policy, 23(1), 3-20. 
Vogel, P. 2015. Generation Jobless? Turning the Youth Unemployment Crisis into Opportunity. Ed. Palgrave-Macmillan: New York.

Wagner, W. 2016. Using IBM ${ }^{\circledR}$ SPSS ${ }^{\circledR}$ Statistics for Research Methods and Social Science Statistics. Sage Publications, Inc., UK.

Wills, A., Tshangela, M., Shaxson, L., Datta, A., Matomela, B. 2016. Guidelines and good practices for evidence-informed policymaking in a government department. Pretoria: Department of Environmental Affairs. London: Overseas Development Institute.

Wunsch, C. 2016. How to minimize lock-in effects of programs for unemployed workers. IZA World of Labor, 288. DOI: 10.15185/izawol.288. 